\title{
Appendix: On Moral Status
}

\author{
By Benjamin L. Curtis and Simo Vehmas
}

\section{Introduction}

As was explained in the first chapter, our research project and this book were initially motivated by philosophical debates regarding the moral status of people with profound intellectual disability. Someone unfamiliar with philosophical discourse may find these debates bizarre at best, for at least two reasons. The first is that a mere speculation about the moral status of persons with PIMD in any other way than affirmative may seem offensive. The other reason is the fact that philosophers often do not bother to communicate their ideas in an accessible manner, which may make their philosophising seem abstruse and insular. While we have tried to do our best to write on these issues as clearly as we could in earlier publications (e.g. Curtis \& Vehmas, 20I6a; Vehmas \& Curtis, 20I7), we have probably succumbed to an unnecessarily technical style of writing as well. Having said that, the issue of moral status is notoriously complicated and it is very difficult to do justice to the whole complexity of it without a degree of technicality. In this appendix, we aim to discuss the issue as clearly as we can and explain what the philosophical issues involved are. Where the material is technical, we try to spell out the concepts involved in detail. We also try to articulate where we think they go wrong, and why it is important that we do.

The philosophical analysis of this appendix has been a parallel project to ethnography. It differs from the rest of the book in that it concentrates on unpacking the strengths and weaknesses

\section{How to cite this book chapter:}

Curtis, B. L. and Vehmas, S. 202I. Narrowed Lives: Meaning, Moral Value, and Profound Intellectual Disability. Pp. I 85-2I 2. Stockholm: Stockholm University Press. DOI: https://doi.org/IO.I6993/bbl.i. License: CC-BY 4.o. 
of different philosophical arguments without discussing the issue in the light of our data. This is simply because we evaluate normative arguments and our data cannot either verify or falsify those arguments. What data can do is to provide empirical material for philosophical arguments and show whether philosophers have used empirical knowledge appropriately. But, as such, data cannot prove whether, for example, psychological or relational properties are the normative foundation of one's moral status. In other words, there is no empirical evidence that would tell us, for example, why it would be wrong to kill people for fun. Solving that kind of question requires conceptual evidence.

The fundamental ethical principle that underpins the project that led to this book is that human beings with profound intellectual disability are beings with moral status equal to, and deserving of the same respect as, human beings without them. This principle entails that the interests and well-being of people with PIMD matter as much as anybody else's, and that those of us who do not have such impairments have a duty to understand them better, in order to discover what those interests truly are and how their well-being might be facilitated. Let us record this principle as follows:

Equality: Human beings with profound intellectual disability have the same moral status as statistically typical non-disabled adult human beings.

We expect the equality principle will strike many readers of this book as blindingly obvious, or as being in some sense self-evident, or undeniable. We expect this because the equality of all humans, no matter what their ability, is often taken to be a foundational moral truth. Its spirit is captured in our fundamental legal documents, and is taken by many to encapsulate the very core of what it is to have civilised values at all. To give just one example, it is captured in the very first line of the Universal Declaration of Human Rights, which reads:

Whereas recognition of the inherent dignity and of the equal and inalienable rights of all members of the human family is the foundation of freedom, justice and peace in the world. (UN General Assembly, I948) 
It may therefore come as a surprise to some to learn that, according to the standard view of moral status in the philosophical literature (known as moral individualism), the equality principle is false. In fact, according to moral individualists, because people with profound intellectual disability lack certain 'status-conferring' intrinsic properties, such as the capacity for high-level thought, they therefore have a lower moral status than non-disabled adult humans, and the same moral status as certain non-human animals (e.g. cattle or rats). As a being's moral status determines how a being may be treated, one consequence of this is that to farm and eat humans with profound intellectual disability is, in and of itself, no worse (morally speaking) than farming and eating cattle. And another is that experimenting on humans with PIMD is, in and of itself, as permissible (morally speaking) as experimenting on lab rats. Moral individualists recognise that there might be instrumental reasons not to do these things (e.g. because it will upset non-disabled people who care about disabled individuals), but there is no non-instrumental reason not to. These consequences are endorsed by those who defend moral individualism. Here, for example, is Jeff McMahan, probably the most prominent defender of the view:

[S] uppose that a certain animal lacks any status-conferring intrinsic property that would make it impermissible to kill that animal as a means of saving several people's lives. Suppose further that there are no [instrumental] reasons that oppose killing it - for example, it is no one's pet. ... According to moral individualism, if it is permissible to kill the animal, it should also be permissible again assuming no [instrumental] reasons apply - to kill, for the same purpose, a human being who also lacks any relevant status conferring intrinsic properties. (McMahan, 2005, p. 355)

We expect many readers will find these consequences morally shocking, and may even think that anyone who endorses them thereby betrays some gross moral failing. But it is important to realise that, within the philosophical literature, it is not only a mainstream view; it is the most widely endorsed view and considered standard by many. And this matters, because philosophical views do trickle out from the academy into society, through popular books, or because philosophers sit on ethical advisory panels 
and are consulted on governmental policy documents with ethical implications. Indeed, McMahan himself sits on such panels, as do other moral individualists. And so it is important that we engage with their arguments in their own terms and attempt to show where they go wrong.

We expect that many readers of this book will be tempted by a very quick response to moral individualism. This is to simply stamp one's foot and declare 'We know all humans have an equal moral status, and that's the end of it!' But we want to urge against giving only this kind of response. It is not that it is a bad response. In fact, as we will see, it is a fundamentally sound response and one that is important to make. But the point is that we should also be interested in taking moral individualism and the arguments in favour of it seriously. We should not be content with saying that moral individualism goes wrong, but also attempt to say where it goes wrong. If we are to deepen our moral understanding of human equality itself, and our understanding of the moral value that humans with PIMD have, a close examination of these arguments is essential.

Before we begin the main discussion, we wish to include a few words of autobiography, for reasons related to what we have just said, and for other reasons that will become clear. We (Benjamin and Simo) have been working on the issue of moral status and profound intellectual disability since 20I0. We began working together precisely because each of us recognised the influence of the arguments put forward by moral individualists against the equality principle, but we also shared the feeling that their conclusions are morally shocking, and that therefore those arguments must be wrong. But, in the spirit of intellectual modesty, we admit that since then we have struggled to say precisely where the arguments of the moral individualists do in fact go wrong. In a pair of early papers we developed an account according to which moral status can be grounded in relational terms (Curtis \& Vehmas, 20I4; Vehmas \& Curtis, 20I7). It is a position that we now, at least partially, reject. However, as we will explain, we do think that that position contained a kernel of truth, and we now think that we have at least the beginnings of a correct response to moral individualism. And so in this appendix we outline the point that we have arrived at. We also admit that we have no fully 
worked out answers and that there is much work still to be done in this regard. The outlines of an alternative position are now becoming clear, but our work here is ongoing, and we still need to work out its details. At any rate, we hope that this appendix gives the reader a good sense of the philosophical debate we are engaged in, its importance, and where we now stand in that debate. We also hope it makes clear that the overall empirical project from which this book issued has serious philosophical underpinnings.

The structure of what follows, then, is this: in Section I we first explain and defend the idea that we can continue to accept the truth of equality without giving a detailed positive account of its truth, and reject moral individualism without being able to say where it goes wrong. Given what we have said above, we nonetheless recognise the importance of saying where moral individualism does go wrong. In Section 2 we explain the basic principle that underlies the moral individualist position: the principle that an individual's moral status must be grounded in the possession of intrinsic properties alone. In Section 3 we explain why moral individualists think that the only intrinsic properties that can do the job are psychological properties, and show why this leads to the rejection of equality. Then in Section 4 we consider what seem to be the only two possible responses to moral individualism - to maintain that all humans are psychologically equal in some important respect, or to adopt a relational account of moral status. We reject both of these responses, but then in Section 5 argue that there is in fact a further (third) response available that has been overlooked. This is to accept that intrinsic properties are important, but that their significance can be relational. We think that this response holds great promise. Finally, in Section 6 we finish by saying a little about how we think it might be developed.

\section{Equality as a Moorean moral belief}

We have already noted that we suspect many readers will be tempted by a quick response to moral individualism, i.e. to reject the view without saying where it goes wrong. Although we have also said we urge against giving only this response, we have also said that this response is fundamentally sound and one that it is important to give. Why is it important? Because moral individualists 
have a very well worked out, unified theoretical position, one that has been developed in a great amount of detail and that is agreed upon by many working in the field. Jeff McMahan, mentioned above, has provided what is, in effect, a book-length defence of the view in The Ethics of Killing (McMahan, 2002), supplemented by numerous journal articles (e.g. McMahan, I996, 2005, 2008, 2009, 2016). And many other philosophers, including James Rachels and Peter Singer, have book-length defences of the same basic view, supplemented by numerous further journal articles of their own (e.g. Rachels, I987, I990, 2002, 2004; Singer, I979, I989, 2010, 2016). Not everything within their books and articles pertain precisely to the issue of moral status and profound intellectual disability. And nor is it the case that the proponents of moral individualism agree on every detail of the view. But everything that they have written forms a more or less coherent network of mutually supporting views that also supports moral individualism. And, even if they disagree on some of the details, they agree on the fundamentals.

In short, then, to oppose moral individualism is to oppose a large body of well-supported unified theory. By contrast, the opposition to moral individualism in the literature is largely unsystematic and often theoretically unsatisfying, for reasons we will come to. While many have written rejecting the view, the positive opposing views have been developed in a multitude of ways, in much less detail, and with little agreement on even the broad outlines of what the correct alternative view should look like (for an overview of the multitude of opposing views, see Wasserman, Asch, Blustein, \& Putnam, 20I7). As such, it is important to give the short answer to moral individualism to thwart the following line of argument from the moral individualists (here we summarise the general moral individualist view of the opposition):

Generally speaking, in every domain of enquiry, we should believe the best current theory. With regard to moral status, that theory is moral individualism. It is true that some have developed other views, but there is much disagreement, and they have not been developed in anything like the same detail that moral individualism has been. As such, the alternative views should be considered promissory notes at best. Until they have been worked out in the same 
level of detail as moral individualism, and shown to withstand criticism in the way that moral individualism does, moral individualism remains our best moral theory and we should continue to believe it. It is true that moral individualism contradicts the equality principle, and so contradicts pre-theoretical moral beliefs, but sometimes we do have to give up our pre-theoretical beliefs when our best theory entails their falsity.

The above line of argument is plausible, but it fails. It fails because, although it is better to have a fully worked out response, we are nonetheless entitled to reject moral individualism, at least on a personal level, without having a fully worked out alternative account available. We now turn to why this is so.

While it is true that we may sometimes have to revise our pre-existing moral beliefs in light of theory, there are limits on what revisions are acceptable. Our moral beliefs, like all beliefs, are held with varying degrees of confidence, and so some are more readily abandoned than others. Those moral beliefs that are very hard to give up are our strongly held core moral beliefs, and that a moral theory is consistent with these is more important than its consistency with our more weakly held peripheral moral beliefs. An example here might be the belief that travelling by aeroplane to go on holiday is morally blameless. Moreover, certain moral beliefs are so strongly held that they act as fixed points in our moral theorising. An example here is the belief that kicking another human to death for fun is morally wrong. This is a moral belief such that our degree of confidence in its truth is invariably stronger than the degree of confidence we might have in any proposed moral theory that contradicts it. We call beliefs of this kind our 'Moorean moral beliefs', after G.E. Moore, who argued that certain kinds of belief are immune from revision due to philosophical argument (Moore, 1939). He illustrated this by considering the belief that each of us can express in the first person using the sentence 'I know that I have hands'. There are various radical sceptical arguments that purport to show that this belief is false (the most famous being Descartes's argument that, for all we know, the external world does not exist at all, and we are being deceived into thinking that it does by a demon). But Moore's point was that 
none of these arguments can ever be successful, for our degree of confidence in their premises can never outweigh the degree of confidence we have in the existence of our hands. In just the same way, we think that the belief about kicking human beings to death for fun is not merely a widely held pre-existing moral belief but a Moorean moral belief - it is a belief that is so central to our moral outlook that it simply not open to revision in the light of theory. More to the point, we think that equality also captures a Moorean moral belief. Thus, one can be confident that moral individualism is wrong, and reject it, even if one does not have a fully worked out alternative theory to offer in its place.

Of course, moral individualists might respond to the above by pointing out that they themselves deny equality, and that, as such, it cannot be a Moorean moral belief (otherwise, they might say, they would not be able to deny it). Our response to this is to note that moral individualist views are formed in something of an empirical vacuum. It is easy enough to deny the Moorean nature of equality and to maintain the lower moral status of humans with profound intellectual disability only so long as such humans are thought of in the abstract, and only so long as one has little physical contact with, and little first-hand knowledge of, what such humans are really like. But we do not think that anyone who has actually spent time getting to know humans with profound intellectual disability could deny that they have the same moral status as non-disabled humans, and so deny the Moorean nature of equality.

To summarise, our basic position is this: our belief in the principle of equality is a fundamental moral belief of such importance that we are entitled to hold it to be true even without having available a theoretical justification for it. In addition, we are personally entitled to reject any moral theory that contradicts it without saying where that theory goes wrong. And so, because moral individualism does contradict equality, we are personally entitled to reject it without saying where it goes wrong. However, for the reasons given above (i.e. because moral individualism is such an influential view), it is also important that we do examine where moral individualism goes wrong. And so it is to this task that we now turn. 


\section{Grounding moral status}

It is worth noting to begin with that moral individualists agree, at least to some extent, with what we have said above. Although they do not think equality captures a Moorean moral belief, they do recognise that it is a highly intuitive principle, and that rejecting it leads to accepting highly counterintuitive consequences like those we signalled in the introduction (e.g. that to farm and eat humans with PIMD is, in and of itself, no worse than farming and eating cattle). They also agree that our moral theories should cohere, in large part at least, with our intuitive moral judgements. However, they think that (in the absence of any other plausible moral theory) moral individualism is strong enough to warrant believing it true, and so strong enough to give up belief in the principle of equality, and to accept the highly counterintuitive results. The basic principle that they invoke, they think, is itself highly intuitively plausible, and allows us to explain a huge number of our pre-theoretical moral beliefs. And for this reason, they think, we should accept that it is true. What, then, is this basic principle? It is this:

Status intrinsicality: An individual's moral status must be grounded in its possession of morally relevant intrinsic properties.

Moral individualists then argue that it is only an individual's intrinsic psychological properties that are morally relevant, and that individuals with profound intellectual disability do not possess such properties sufficient to ground a high moral status. So, they think that the principle of equality cannot be maintained. Let us spell out this view in more detail.

We start off with the idea of 'grounding'. Status intrinsicality contains the notion that moral status must be 'grounded' in further properties. What does this mean? The general idea is that a property needs to be grounded when that property is not a simple unanalysable one, that is, one that cannot be defined or explained in terms of any more basic or simple property. Plausible examples of properties that are simple and unanalysable, and so do not need to be grounded, are the fundamental physical properties like mass and charge. For example, electrons are taken by physicists to be fundamental particles - they are not 'built up' from any more 
fundamental particles. They are basic carriers of charge, specifically negative charge. So, physicists say that electrons are objects that possess the property of having a charge of $-I$. The 'having of this property' is not explainable in any more basic terms. It is simply a brute fact of nature: electrons have such a charge, and that is all there is to say about the matter.

To return now to status intrinsicality, the principle states that an individual's moral status cannot be fundamental in the same way that an electron's negative charge is fundamental to it. The idea is that there must be something more we can say, some further property or properties in terms of which its possession by an object (in this case a person) can be explained. It is useful to consider some simple examples to illustrate. Consider shape properties, for example the properties of being square and of being round. These are properties of macroscopic objects - TV sets are square, and beach balls are round, for example (very roughly speaking). But, we can ask, are these simple, unanalysable properties of these things, or are they grounded in some more fundamental properties? And here the answer is quite clear. They are not simple unanalysable properties. TV sets are square because they are made up of fundamental particles arranged in a certain way (i.e. squarewise) and beach balls are round because they are made up of fundamental particles arranged in a different way (i.e. roundwise). That is to say, being made of particles arranged squarewise explains why TV sets are square, and being made of particles arranged roundwise explains why beach balls are round. Thus, shape properties are grounded in the further property of being made up of particles arranged in a certain way.

However, there is more we can say about this simple example. Being square and being round are both intrinsic properties of objects. That is, whether an individual possesses the property of being square or being round depends only on the way that thing is in itself, and does not depend on the way that any other thing is. Roughly speaking, you can tell that something is square, for example, just by looking at it. You do not need to consider any other thing. Contrast shape properties like this with familial properties of persons like being a sibling. These latter properties, unlike the former, are extrinsic or relational properties. That is, 
whether a person possesses the property of being a sibling depends on that person standing in relations to some other thing. Roughly speaking, again, you cannot tell that someone is a sibling just by looking at her or him alone. Barack Obama is a sibling, for example, and this is not a simple unanalysable property of him. But in this case what grounds the fact that he is a sibling is not that he is himself a certain way, but rather that he stands in certain familial relations to some other things, i.e. his brothers and sisters. Thus, the property of being a sibling is grounded in the fact that things possessing them bear certain relations to other things.

The above examples, then, enable us to spell out the moral individualist position more clearly. Moral individualists hold that a person's moral status is, like a ball's roundness, not a simple unanalysable property, and so must be grounded in some further property or properties of the person. And, they maintain, a person's moral status is an intrinsic property, and so again akin to a ball's roundness (rather than, for example, a person's being a sibling). So, they maintain, an individual's particular moral status cannot be grounded relationally, that is, in terms of what relations that individual stands in to other things, but must instead be grounded in the possession of some further intrinsic property or properties of the individual themselves.

Let us take stock. So far all we have done is explain the content of the basic principle held by moral individualists, i.e. status intrinsicality. According to that principle, moral status must be grounded, and it must be grounded by the possession of intrinsic properties. We have not, as of yet, explained why they think status intrinsicality is true. We will come to that in due course. But, for now, let us suppose that it is true, and consider what follows from it.

\section{Intrinsic properties as the grounds of moral status}

If we assume that an individual's moral status must be grounded in its possession of further intrinsic properties alone, and we wish to maintain equality, meaning that all human beings have an equal moral status higher than that of any non-human animal, it follows that that there must be some intrinsic difference between all 
human beings on the one hand and all non-human animals on the other that explains this. But what can this difference be? It seems that there is no plausible candidate.

One obvious candidate of an intrinsic property that is shared by all humans and no non-human animal is the purely biological property of being human (i.e. of having the genetic constitution of a human being). But moral individualists reject this property on the grounds that a purely biological property is not a morally relevant property. On this score, they have a point. It is indeed hard to see how being made up of cells comprised of certain kinds of nucleic acid sequences could, in and of itself, explain why an individual has any kind of moral status at all. Consider asking: 'Why should I not torture this human being? Why would it be wrong to do so?' And consider the reply: 'Oh, because the adenine, guanine, cytosine and thymine in the cells that make up that person's body are ordered in a special way.' This, it is clear enough, offers no explanation whatsoever (i.e. it is entirely unilluminating).

If intrinsic biological properties cannot do the job, what other intrinsic properties can? Simply put, moral individualists maintain that none can. They think, in short, that there are no morally relevant intrinsic properties that are shared by all humans and no non-human animals. This is because they think the only kinds of intrinsic property that can do the job of grounding moral status are psychological properties. It is only psychological properties, they maintain, that can do any explanatory work. And because certain human beings, and in particular people with profound intellectual disability, lack psychologies sufficient to ground a high moral status, they possess a lower moral status than non-disabled human beings.

Consider that the intrinsic psychological properties stressed by moral individualists are those such as the capacity to feel pain and emotion, to reason and reflect, to think, to plan for the future, and to regret the past. To see that they can do the explanatory work moral individualists are so impressed by, consider that human beings have the capacity to feel pain. And now consider asking the question we considered above once more: 'Why should I not torture this human being? Why would it be wrong to do so?' Unlike the previous answer we considered (i.e. the one framed in 
terms of genetic properties), the following answer does offer an explanation and is illuminating: 'Because it would cause her to feel extreme levels of pain.' If one recognises the badness of pain, one can appreciate that torturing a human being is wrong because it would give rise to pain. In other words, that it would give rise to such pain is what explains why it is wrong.

Both humans and non-human animals can feel pain, of course, and so the above explanation for why it is wrong to torture a human being also applies to non-human animals. In this regard, then, there is no difference between humans and non-human animals. However, moral individualists do allow that there is a difference between some human beings and at least some (and perhaps all) non-human animals - a difference that is grounded, it should now be clear, in a difference in intrinsic psychological properties. Specifically, they argue that the possession of high-level psychological properties (e.g. the ability to entertain propositions in thought, to reason, to form a conception of oneself and one's life as a coherent whole) give rise to reasons to treat those who possess them in a certain way, and that those reasons simply do not hold in the case of those, like some non-human animals such as sheep and cattle, who lack high-level psychological properties. For example, moral individualists argue that their view can explain why it is morally worse to farm and eat human beings possessing high-level psychological properties than it is to farm and eat cattle. What explains this, they can say, is that the former possess high-level psychological properties and the latter do not. Thus, the possession of high-level psychological properties is thought by moral individualists to be 'status-conferring': humans with high-level psychological properties have a higher moral status than non-human animals that lack them.

So, moral individualists want to explain the general difference in moral status between humans and non-human animals in terms of the possession of high-level intrinsic psychological properties. Generally speaking, they think, humans have a higher moral status than non-human animals because humans possess high-level psychological properties that non-human animals lack. Here there is some disagreement about the details among moral individualists. They disagree about the precise way to spell out 
how the possession of high-level psychological properties confer status in this way. But all are agreed that they do confer such a status. To give one example of how this is spelled out, though, we can consider Jeff McMahan's account. He argues that individuals who possess high-level psychological properties have available to them higher levels of well-being. Although non-human animals may lead lives containing simple exuberant joy, for example, humans who possess high-level psychological properties lead lives containing more complex psychological goods, which, he maintains, are therefore better lives (i.e. are lives that contain more well-being). Hence, he argues, it is morally worse to kill a human who possesses high-level psychological properties than it is to kill a dog, because the lives that humans lead are better (contain more well-being) that those that dogs lead, and so such humans lose more than dogs do by being killed:

[I]t seems that even adult human life tends to contain its share of exuberant joys that rival in intensity those experienced by dogs. They are simply not so conspicuous as they are within the lives of dogs, where they dramatically punctuate days otherwise given over to torpor and sleep. Human well-being, by contrast, is more continuous, dense, and varied, so that the ecstatic moments, which may be more diffusely spread over longer periods, are less salient. And what fills the intervals between these moments is normally altogether better than the dull vacancy of a dog at rest. ... Hence, assuming that a typical person's future would be of a significantly higher quality than that of a typical animal (of whatever species), the conclusion [is]: persons typically lose considerably more good by dying than animals do. (McMahan, 2002, p. I96)

Along similar lines, Rachels (I986) presents the life of Bertrand Russell as an example of 'an extraordinarily full life' (p. 50) and says that "in most cases the life of a "normal" human is to be preferred to the life of a mentally retarded human' (p. 58) because the mentally retarded human would not be able to live a complex life like a 'normal' human who has got more to lose than the 'retarded' human:

A young woman dies: it is bad because she will not get to raise her children, finish her novel, learn French, improve her backhand, or do what she wanted for Oxfam; her talents will remain 
undeveloped, her aspirations unfulfilled. Not nearly so much of this kind could be said about a less sophisticated being. Her death is worse because there are more reasons [emphasis in original] for regretting it. (Rachels, I986, p. 57)

We are now in a position to see more clearly why moral individualists hold that humans with profound intellectual disability have a lower moral status than non-disabled humans, and equal to that of some non-human animals. The reason is that, according to moral individualists, although humans with profound intellectual disability possess the capacity to feel pain (just as both humans and non-human animals do), they lack high-level psychological properties (just as non-human animals such as cattle do, but unlike non-disabled humans). And so, although humans with profound intellectual disability possess some status-conferring intrinsic psychological properties, they do not possess those required to confer the high moral status had by non-disabled humans. They are, in this sense, psychologically comparable to non-human animals like cattle. And so, because it is only intrinsic psychological properties that can ground moral status, humans with profound intellectual disability possess the same moral status as non-human animals, and a lower moral status than non-disabled human beings.

\section{Relational accounts of moral status}

If we agree, as we think one should, that moral status properties are not simple unanalysable properties, then there is an onus upon us to explain its grounds. We do think that moral individualists have a point that purely biological intrinsic properties (like having a certain genetic constitution) cannot by themselves do this job. And we can think of no intrinsic properties other than psychological ones that can plausibly do the job by themselves either. So, how are we to respond to moral individualism? It seems that there are only two responses available. The first is to argue that, despite what moral individualists think, human beings with profound intellectual disability $d o$ possess psychological properties that set them apart from non-human animals and that explain why they have a higher moral status than them. The second is to reject the idea that only intrinsic properties can ground 
moral status, and instead adopt a relational account. We consider and reject the first response, before turning to the second, which will occupy us for the rest of this section. It comes, in fact, in two guises, both of which we will argue also fail. However, considering the second response will enable us to see that there is in fact another (i.e. a third) response available, and it is one that is much more promising. We then consider that response in Section 5 .

With regard to the first response to moral individualism, then, the salient question to ask is this: is it really true that humans with profound intellectual disability are psychologically comparable to non-human animals? Some scholars have argued that this is not the case, and that, despite suffering from reduced psychological abilities, those with profound intellectual disability still possess a distinctive kind of buman psychology, which explains their high moral status. Eva Feder Kittay, for example, has written in such a vein about her daughter, Sesha. She writes:

I am not going to rehearse the things that Sesha can or cannot do and what a dog can or cannot do. Such comparisons are otiose and odious as well as senseless. What Sesha can do she does as a human would do them, though frequently imperfectly, but it is humanly imperfect, not canine perfect. However, even with all that Sesha cannot do and seems not to be able to comprehend, her response to music and her sensitivity to people is remarkably intact. Perhaps her responsiveness to music is more than remarkably intact; it is quite simply remarkable. What a discordant set of abilities and disabilities she exhibits! This unevenness is a feature of many severely and profoundly retarded persons. (I will now stop calling them 'individuals' and begin to speak of those with severe cognitive impairments as the persons I believe they are.) Such unevenness is not a feature of the animals with whom McMahan equates them. (Kittay, 2005, pp. 27-28)

We agree entirely with what Kittay says here. But there is another sense in which we disagree, and it is the latter sense that is relevant to a proper assessment of moral individualism.

The sense in which we agree is this: it is entirely clear from what Kittay writes that her daughter, Sesha, does indeed possess psychological capacities of a sufficiently high level to ground a high moral status (i.e. one equal to that possessed by non-disabled 
humans). However, this itself is not a relevant fact in criticising moral individualism. Moral individualists are quite clear that they are not using the term 'profound intellectual disability' in any kind of diagnostic sense. That is, they are not claiming that all individuals diagnosed with profound intellectual disability have a lower moral status than non-disabled humans. Instead they explicitly use the term 'profound intellectual disability' (or some other equivalent term) by definition to mean 'those human beings who do, as a matter of fact, lack the relevant high-level psychological properties sufficient to ground a high moral status' (see, for example, McMahan, 2005 , p. 358 for an explicit statement to this effect). ${ }^{32}$

We think that moral individualists could have chosen a different way to express themselves in order to avoid confusion on this matter (and to avoid causing undue offence), but this is not a substantive criticism of their position itself. If they are to be shown to be wrong, what needs to be shown is not that some of those diagnosed with profound intellectual disability in fact possess psychological properties of a sufficiently high level to ground a high moral status. Instead, what needs to be shown is that there do not exist any humans who lack such properties. And this, we submit, is not credible. Given that profound intellectual disability falls on a spectrum, it seems highly likely that there do exist human beings for whom it is not plausible that they possess any high-level psychological properties. Perhaps it can be maintained that such humans do still possess a distinctly human psychology, but this does not mean they are not psychologically comparable to non-human animals in a morally relevant sense. To say that such humans are psychologically comparable to non-human animals is not to say they have the psychology of a non-human animal, but only that their psychology is at an equivalently developed level to that of non-human animals such as cattle. It does not matter whether they have psychologies that are different from

${ }^{32}$ It seems that moral individualists (at least McMahan) are not talking about people like Sesha when they use expressions such as 'severely mentally retarded'. This raises the question about the empirical relevance of their arguments, which, in our view, moral individualists overlook; in order to have any relevance, the conceptual claims in this context require empirical substantiation (Vehmas \& Curtis, 2017). 
the psychologies of non-human animals, only that they are comparable in this sense. And so, because it seems likely that there are humans with psychologies that are comparable in this sense, we conclude that the first response to moral individualism fails.

We turn now to the second response to moral individualism. This is the rejection of the idea that it is only intrinsic properties can ground moral status. To give this response is to maintain that moral status properties can be like a person's property of being a sibling rather than a ball's property of being round, and in particular that the high moral status possessed by humans with profound intellectual disability is like this. It is thus to maintain that what explains why humans with profound intellectual disability have a high moral status is that they stand in certain relations to other things - that is, to give a relational account of moral status itself.

This has been a popular response to moral individualism, and in fact it is one that we have previously defended. Before we come to this, though, first note that anyone who defends a relational account of moral status faces two challenges: (I) to give an account of which relations are constitutive of the high moral status possessed by humans with profound intellectual disability, and (2) to give an account of how standing in those relations explains why such individuals have a high moral status. The first challenge has been met in a number of different ways by different writers. Some have argued that the relevant relation is simply the biological relation of co-membership in the human species (e.g. Scanlon, I998). Others, recognising that citing purely biological relations face the same kinds of difficulties that citing purely biological intrinsic properties face, have emphasised the idea that it is in fact broadly social relations that matter, although the kinds of social relation appealed to differs. ${ }^{33}$ In an earlier publication, we, for example, called the relevant relation 'the human community relation' and described it as follows:

It is the relation that each of us stands in to each other by being a member of the human community. It is the relation that holds

33 This is the view taken by Kittay (2005) and our previous selves (Curtis \& Vehmas, 20I4; Vehmas \& Curtis, 20I7), among others (other examples include Mullin, 20I I and Jaworska \& Tannenbaum, 20I 5 ). 
between a human and the rest of the human community when he or she is born of human parents, brought up and cared for by humans, and in general, treated as a human within the human community. We don't intend the brief list in the previous sentence to be taken as anything like a list of necessary conditions. The relation holds between different individuals and the rest of the community in different ways. It holds between you and the rest of the community because you participate fully within in it. For example, you vote, work, and pay taxes, as well as engage in emotional and social interactions with other humans. It holds between humans with [profound intellectual disability] and the rest of the human community in a different way. They cannot vote, work, and pay taxes, for example [but] it is not required that those who are related to the human community participate within the human community, in the sense of partaking in those activities that [statistically] normal human beings take part in. All that is required for the relation to hold is that an individual is taken into the human community: that he or she is treated by the community as human. (Vehmas \& Curtis, 20I7, p. 510)

However, we now think a relational view of this kind, no matter which relation is cited as being relevant, cannot be defended. We think this because we now do not think the second challenge can be met. It is not possible to give an adequate account of how standing in a relation of any sort can explain why an individual possesses a high moral status (or, indeed, any moral status at all).

To see why this is so, we want to first consider an objection from McMahan to the kind of view we previously defended. We think that the objection fails - but considering it will lead us to a more powerful objection that we think succeeds (as we will see, there is a sense in which it is in fact a simpler objection). McMahan's objection, then, is this:

[I]f the only factor that relevantly differentiated [those with profound intellectual disability] from animals with comparable capacities was that [those with profound intellectual disability] are specially related to us, it would follow that it would be permissible, other things being equal, for those who are not specially related to them to treat them in the ways in which we treat animals... This means that, if intelligent and morally sensitive Martians were to arrive on Earth, they would be justified, other things being equal, in treating [humans with profound intellectual disability] in the 
ways in which we treat animals with comparable capacities. They would, of course, be required to exercise forbearance out of respect for us, for we are (or at least some of us are) specially related to [those with profound intellectual disability]; thus any harms the Martians might inflict on [those with profound intellectual disability] would constitute indirect offenses against us. But this would, it seems, be the only reason Martians might have not to subject [those with profound intellectual disability] to forms of treatment that we reserve for animals: for example, eating them, hunting them, experimenting on them, and so on. It is doubtful that this conclusion would be congenial to commonsense intuition. If that is right, an appeal to the special relation we bear to [those with profound intellectual disability] cannot provide a full justification for our treating animals considerably less well than we believe we are required to treat [those with profound intellectual disability]. (McMahan, 2002, pp. 222-223)

In other words, McMahan claims here that, although we might save the view that we (i.e. humans) ought not to farm and eat humans with profound intellectual disability by endorsing a relational account of moral status (i.e. such an account would give us a moral reason not to do this), such an account is still open to the objection that this would not apply to those (such as intelligent Martians) who do not stand in the appropriate relation to such humans (i.e. it would not provide them with a moral reason not to do this). If this objection were correct, we think it would show that a relational account cannot work. Our pre-theoretical view regarding the fact that humans possess the moral status that they do, we think, is the view that this is a categorical or objective fact about them - it is the view that every possible rational agent in every possible circumstance ought to treat them with due respect (and so, for example, must refrain from farming and eating them). It is thus not only that we ought not to do certain things to individuals with moral status properties that needs to be explained by an account of moral status, but that these things ought not be done to them by any rational agent under any circumstances. So, if an account of the moral status of humans with profound intellectual disability (or any other human, for that matter) turned out to allow that some possible moral agent could permissibly farm and eat them, or that there was some possible circumstance in 
which this was so, then the account must fail. Then it would not deserve to be called an account of moral status at all. ${ }^{34}$

Now, as it happens, we think that McMahan's objection does not in fact show that relational accounts cannot explain the categoricality and objectivity of moral status, for it is possible to maintain that an individual can gain a categorical and objective moral status by standing in a relation to other things. As we put it in our 2017 paper:

The bestowment view, then, is the view that objective [status] can be bestowed upon an individual by its standing in a relation to something else. Once bestowed, that value then functions to bind all evaluators, not merely those who stand in the bestowing relation to it. In a case where these values are moral values, their being possessed can then give rise to obligations that hold objectively. (Vehmas \& Curtis, 20I7, p. 508)

However, we also now think that there is an objection that does show that a relational account cannot explain the categoricality and objectivity of moral status. In fact, the objection is a perfectly simple one. To see what it is, first note that if any individual's moral status is entirely constituted by the holding of certain relations, then if those relations were to have failed to hold, then that individual would not have had that moral status. Next, note that the kinds of relations cited as constituting the moral status of humans with profound intellectual disability are purely contingent relations; they do not hold as a matter of necessity (in any sense of 'necessity'). And so there could be possible circumstances in which those relations do not hold, and humans with profound intellectual disability would fail to possess a moral status. In such circumstances, it would then be permissible for

34 We are, in this sense, moral realists. We think that moral reasons are objective and apply to all rational agents. We are aware that many outside of the philosophical literature hold 'constructivist' positions according to which morals are constructed by us, and thus are not binding on all rational agents. We do not have the space to evaluate this view here, but we think that adopting such a view is a grave error, for ultimately it leaves its proponents with no grounds whatsoever to rationally criticise divergent moral views, even those they themselves find most pernicious. 
intelligent Martians to treat humans with profound intellectual disability as it is permissible to treat non-human animals. They would do nothing wrong by farming and eating them (or at least nothing worse than we do to non-human animals like cattle). And so, relational accounts must fail.

\section{A further response to moral individualism is possible}

Let us briefly summarise the position we have arrived at. We have outlined the moral individualist's account of moral status, according to which the moral status of humans with profound intellectual disability must be grounded in the intrinsic psychological properties of those humans. However, such humans may not possess any intrinsic psychological properties sufficient to ground a high moral status. Accordingly, we have considered how we might respond to moral individualism. However, as we have outlined, it seems that the only alternative account available is a relational account of moral status, which fails for the reasons just given. So, we think that both moral individualism and relational accounts of moral status fail to account for the moral status of those with profound intellectual disability. Where do we go from here?

In fact, we think that we can learn from the failure of both accounts. Moral individualism fails because it fails to identify an intrinsic property possessed by humans with profound intellectual disability that explains why they have a moral status equal to non-disabled human beings. And relational accounts fail because they fail to identify relations that can do this job. But what if we combine the two accounts? What if we could find an intrinsic property possessed by all humans (with or without profound intellectual disability) that has a relational significance? In fact, we now think that we can do just that.

In order to explain this idea further, it is useful to reconsider the simple examples of grounding that we began with. We contrasted shape properties of objects like being square with familial properties of persons like being a sibling. The former, we said, gives an example of a property that is grounded by intrinsic properties, and the latter an example of a property that is grounded by relational properties. We then went on to say that moral individualists view moral status properties as being like being square and that those 
who defend relational accounts view moral status properties as being like being a sibling. However, there are properties that, in a sense, fall into a half-way house between being square and being a sibling. For these properties, it is unclear whether they should be thought of as being grounded by intrinsic properties or relations. One plausible example, in this regard, is the colour properties of objects, such as being red. Colour properties are certainly not simple unanalysable properties, and so must be grounded. However, there is a sense in which the possession of being red by an object is grounded by intrinsic properties of the object, and a sense in which its possession is grounded by relations. The sense in which it is grounded by intrinsic properties is the sense according to which something is red just if it has a certain intrinsic physical structure that means it reflects light only of a certain wavelength, that is, according to something like the following schema:

$\mathrm{X}$ is red $=\mathrm{X}$ possesses an intrinsic structure $\mathrm{Y}$ that reflects light of a certain wavelength.

And the sense in which it is grounded relationally is the sense in which something is red only if it looks red to normal observers under normal conditions, that is, according to something like the following schema (which mentions other things other than the individual itself, i.e. observers):

$\mathrm{X}$ is red $=\mathrm{X}$ would give rise to red experiences in normal observers under normal conditions. ${ }^{35}$

The salient point here can be put in the following way: if we want to explain what colour properties are, what we should do is explain their intrinsic structure, and explain how that intrinsic structure interacts with the environment to give rise to certain experiences in observers. In other words, being red is a matter of having a certain intrinsic structure that has a relational significance.

Our leading idea, then, is that moral status properties are just like colour properties in the above sense. What we need to do is to

35 NB The notion of a 'normal observer' and 'normal conditions' needs to be spelled out carefully. There is a large literature on how to do this, but we pass over this complication here. The intuitive notions are clear enough for our purposes. 
identify certain intrinsic properties possessed by all humans (including those with PIMD), as moral individualists think we must. But, unlike moral individualists, we do not think that we must confine ourselves to thinking that those properties only have an intrinsic significance, meaning that we can explain why those properties give rise to the possession of a high moral status by considering only humans with profound intellectual disability. Instead, we think we must look to explain their significance relationally, that we must make reference to things other than those with profound intellectual disability to explain why they are morally relevant properties.

We need not stop there. We can draw further on the failure of moral individualism and relational accounts of moral status to learn more about what an explanation of moral status of people with profound intellectual disability must look like. We noted that any explanation of their moral status must account for its categoricality and objectivity; it must explain why any possible rational agent in any possible circumstance must treat those with profound intellectual disability with the respect we maintain they deserve. And the account we are now considering gives us a way to do this. What we must do is identify an intrinsic property possessed by those with profound intellectual disability that any rational moral agent, by virtue of being a rational moral agent, must respond to. It is the relational fact that any rational moral agent must so respond that will explain the significance of the intrinsic property itself. It is this that is missed by moral individualists, who think that the moral status of people with profound intellectual disability is to be explained by mention of their intrinsic properties alone. But there is also something here that is missed by those who defend relational accounts of moral status. If such an account is to work, there must be some intrinsic property possessed by all humans with profound intellectual disability for rational moral agents to respond to in the first place. If there is no such property, there is simply nothing that rational moral agents must respond to, and so no way to establish the necessity of the relation in question, which is precisely what is needed to establish the categoricality and objectivity of the moral status of people with profound intellectual disability. 
So, to summarise the above: what we need to identify is some intrinsic property possessed by all humans with profound intellectual disability and lacked by non-human animals like cattle, and explain its moral significance relationally by explaining why any rational moral agent, by virtue of being a rational moral agent, must respond to it by treating people with profound intellectual disability with the same respect with which they treat non-disabled humans. To put things another way, what we learn from the above is that the most important questions to ask in moral theory are not merely questions about single individuals but those questions along with questions about pairs or groups of individuals and the relations between them.

To apply the above idea to the debate surrounding humans with profound intellectual disability, we should build our theories about what we owe such humans on an explanation of what moral value our relations with them have. In so doing, we should focus on the intrinsic properties possessed by those with profound intellectual disability, but not solely on their intrinsic properties. We should also consider how our intrinsic properties and how we, as rational moral agents, should respond to their intrinsic properties by virtue of being rational moral agents. That is to say, we should not forget to leave out the role we play in the story, as responders to the properties they possess.

\section{Possible personhood and the virtue of empathy}

We take our cue in this final section from a recent paper by the philosopher Shelly Kagan, who has tentatively argued that the intrinsic property of possibly being a person is a property with moral significance (Kagan, 20I6). We think that this view has great promise, so long as it is worked out in line with the basic idea we have expressed above (Kagan himself frames it in moral individualist terms). Here we offer some tentative suggestions about how this might be done.

Firstly, what is the property of possibly being a person? To explain this, we must first explain what the property of being a person is, which is used in a semi-technical sense in the philosophical literature. It is used to pick out the property that is possessed by 
all statistically typical adult human beings by virtue of their possessing the high-level intrinsic psychological properties mentioned above in Section 3. In short, a person in the philosophical sense is an individual with reason and reflection, who is capable of entertaining propositional thoughts, planning for the future, and so on. And so possibly being a person is the property that is possessed by any individual who is not in fact a person (i.e. who does not in fact possess those high-level intrinsic psychological properties) but who could have been (i.e. who could have possessed those high-level intrinsic psychological properties). The idea, then, is that it is an intrinsic property of humans with profound intellectual disability that they could have been persons (in case they are not). This in turn is justified in terms of the metaphysical nature or essence of what it is to be a human being. Human beings, in their very nature, could have been persons, while non-human animals could not. Cows, for example, by virtue of being intrinsically cows, could not have possessed the high level of intrinsic psychological properties that statistically normal non-disabled humans possess. Thus, no cow could have been a person.

If the above is right, this identifies an intrinsic property, that of possibly being a person, that is possessed by all humans with profound intellectual disability, and lacked by non-human animals. How, then, are we to explain its relational moral significance? Our answer is to appeal to something like a virtue ethical account, according to which it is constitutive of being a good moral agent to respond to this property appropriately, by conferring greater care and concern upon those who could have been persons than those who could not. One initial line of thought is to appeal to something like the virtue ethical notion of empathy. We may suppose that empathy comes in different forms, and that it takes a special form with regard to humans with profound intellectual disability. Thus, we can say, one should empathise in this special way with those who could have been persons but are not. These humans have sustained something like an existential loss in that they do not possess all the attendant goods that go along with being a person. And, because of this, they are owed a great deal of empathy, in the special sense we have indicated. Any moral agent should respond to their existential loss appropriately, by 
treating such individuals with utmost respect, as having a moral status equal to the rest of human beings. We suggest that properly spelled out this special notion of empathy entails acting towards such individuals with a special concern with their well-being. It involves making an attempt to understand what that wellbeing consists in, and in attempting to make their lives go as well as possible. ${ }^{36}$

Thus, the idea here is that any rational moral agent, by virtue of being a moral agent, should respond to this intrinsic property of people with profound intellectual disability by treating the individuals in question with the utmost respect, i.e. as having a moral status equal to that of non-disabled human beings. To be somewhat more specific, we suggest that acting empathetically in this special sense towards such individuals involves being concerned with their well-being to a higher degree than we are concerned with the well-being of non-human animals like cattle. Note, however, that this is an initial tentative account. We do not mean to hang our account here on precisely the notion of 'empathy'. Although this term seems appropriate in some respects, it seems inappropriate in other respects, and perhaps another term is better. In particular, 'empathy' may seem to suggest something like 'pity', which we do not intend. A good analogy here is perhaps with the elderly, who are no longer able to do the things youth allows because of the bodily changes that naturally occur

${ }_{36}$ This line of thought has a resemblance to the Rawlsian idea that the undeserved inequalities resulting from natural and social lottery should be compensated for somehow (Rawls, I97I). So, persons with PIMD in this scheme have suffered from bad luck in the natural lottery by being born with less favorable biological potential than the rest of us. Often, they have been unlucky in the social lottery as well by living in a social environment that caters poorly to their various needs. To admit that PIMD as an inherent state of an individual is more or less undesirable does not necessarily imply ableism, derogatory pity or any other harmful prejudice where disabled people's subjectivity is taken away from them and where they are nothing but objects on whom non-disabled people project fears about their own vulnerability. Rather, the acknowledgement of the undesirable dimension related to PIMD is an opportunity for moral agents to pay extra attention to the well-being of those fellow human beings who possess only rudimentary capacities of their own to flourish. 
as humans age, and have thereby sustained a loss. Those who are younger should empathise with them for this, and treat them in an appropriate manner because of this, but this does not amount to pity. At any rate, a proper treatment of the issue will need a thorough exploration of what the virtues consist in, and how responding to those individuals with profound intellectual disability because they could have been persons, is partly constitutive of being a virtuous agent. We are not yet sure how to spell this account out in detail. But it does have an intuitive appeal, and we are convinced that some account of this kind can be made to work.

\section{Conclusion}

The above, then, is where we currently stand on these issues. Clearly, details need to be filled in, and further development is needed. But, if we are right, all the pieces of the puzzle will finally fall into place. We can allow that humans with profound intellectual disability possess an intrinsic property, that of possibly being a person, and maintain that it is the relational significance of this property that grounds their high moral status. Some of them could have been persons, but are not, and this is something any good moral agent should be appropriately responsive to, by displaying some virtue, perhaps one related to that of empathy. And so any good moral agent should be concerned to ensure that the well-being of humans with profound intellectual disability is fully understood, so that their lives can go well.

We finish, then, where we began, by restating the fundamental ethical principle that underpins the project that led to this book: human beings with profound intellectual disability are beings with moral status equal to, and deserving of the same respect as, any other human being. As we also stated at the beginning, this principle entails that their interests and well-being matter as much as anybody's, and that we therefore have a duty to understand them better, in order to discover what those interests truly are, and what their well-being truly consists in. As we hope to have demonstrated in this appendix, we now think that we have, at least in outline, an understanding of how this is to be justified philosophically. 